\title{
Bulk Genomic DNA PCR Analysis-A Rapid Method to Estimate Genetic Relatedness among Heterogeneous Lucerne (Medicago sativa L.) Cultivars
}

\author{
Amaresh Chandra \\ Plant Physiology and Biochemistry Laboratory, Indian Grassland and \\ Fodder Research Institute, Jhansi-284003, India
}

Received August 6, 2007; accepted August 20, 2007

\begin{abstract}
Summary In the present investigation a method is demonstrated using bulk samples of genomic DNA to estimate the genetic relatedness among heterogeneous lucerne cultivars through RAPD markers. Each of 7 random primers employed generated 5 to 10 DNA fragments from the individual plant of 5 cultivars as well as bulked samples made of several plants per cultivar. The genetic distance (D) calculated from RAPD patterns obtained with bulked DNA samples ranged from 0.03 to 0.11 which largely corresponds to their known relatedness. The RAPD profiles of the bulk samples containing DNA from different numbers of individuals of the cultivars indicated bulking of 10 individuals DNA are necessary to get the representation of the most of the bands of the cultivars. Thus, the method demonstrated could be useful for estimating genetic relatedness among the heterogeneous crop like lucerne.
\end{abstract}

Key words Genomic DNA, RAPD, Lucerne, Genetic distance, Index of genetic distance, PCR.

Information about germplasm diversity and relationship among the breeding materials or potential lines to be used in breeding programs are main prerequisites in their improvements and plant breeding per se. Molecular characterization and genetic relationships studies are much more challenging for those crops species, which are out-crosser, and normally suffers severe inbreeding depression. Alfalfa commonly known as lucerne is one such crop which is grown more than one million hectare of lands in India (Hazra 1995). Moreover, being allo-gamus and auto-tetraploid in nature exhibited by natural and cultivated populations of alfalfa ( $M$. sativa L.), out-crossing nature of the crop further maximizes the genetic diversity among and within the populations. Five cultivars of lucerne, namely Co-1, LLC-3, RL-88, Anand-2 and T-9, largely occupy major parts of the lucerne growing areas of the country. Studying genetic relationships among these and other cultivars of this crop species is lacking due to their highly heterogeneous nature as each and every plant of the cultivars behaves differently. Therefore, the estimation of intra-cultivar variability based on individual plants of a cultivar is an arduous task. To minimize the work load of estimating individual plant of a population and to increase the efficiency of the estimation of genetic variability, bulking of genomic DNA of a set of plants is demonstrated which not only reduces the cost of estimation but also provide the increased efficiency of the estimation of genetic diversity.

Though isozyme analysis have been used to distinguish between homozygous from heterozygous individual and to determine the degree of genetic variability in plant populations, its use is limited because of the low number of loci that are available and change of isozyme patterns with the plant development (Tanksley 1983, Tanksley and Orton 1983). RFLPs are available in almost unlimited numbers but their detection by Southern blot hybridization is expensive, time consuming

* Corresponding author, e-mail: amaresh62@yahoo.com 
and technically complex. Moreover, this is not feasible when RFLP is performed with randomly selected genotypes within a population, followed by comparison of marker frequencies between population due to large numbers of genotypes and population are to be characterized. Random amplified polymorphic DNA (RAPD) protocol, which is relatively simple, rapid and does not require prior sequence information, is preferred (Williams et al. 1990). However, its practical application to genetic studies of heterogeneous population is limited in cases where large number of individuals need to be examined from a population or cultivars. Yu and Pauls (1993) have proposed bulking of DNA samples over multiple alfalfa genotypes and demonstrated its utility using 4 populations. The concerns about the technique, like obscuring of low-frequency fragments could be only satisfied when examination is conducted with the prevalent cultivars like Co-1, LLC-3, RL-88, Anand-2 and T-9 in the present case. Therefore, in the present investigation a method employing polymerase chain reaction (PCR) of bulk genomic DNA samples of 5 important cultivars of lucerne is demonstrated. The study shows usefulness of the method in distinguishing different cultivars and for estimating genetic relatedness.

\section{Materials and methods}

\section{Plant materials and DNA extraction}

Plant materials of 5 cultivars (Anand-2, Co-1, LLC-3, RL-88 and T-9) of alfalfa (Medicago sativa L.) were grown at research farm of IGFRI, Jhansi in 2004-05. Fresh and young leaves of 15 individual plants of each cultivar were used to isolate the genomic DNA. A trifoliate leaf was ground in extraction buffer consisting Tris- $\mathrm{HCl} \mathrm{pH} 7.4,5 \mathrm{M} \mathrm{NaCl}, 0.5 \mathrm{M}$ EDTA and 10\% SDS in sterile Eppendorf tube using pestle. The slurry was incubated at $60^{\circ} \mathrm{C}$ for $30 \mathrm{~min}$. The homogenate was centrifuged at $8000 \mathrm{rpm}$ for $10 \mathrm{~min}$. Supernatant was taken into fresh tube and DNA was precipitated using isopropanol. The DNA was pelleted by centrifugation. After air drying, the pellet was dissolved in $200 \mu \mathrm{l} \mathrm{TE} \mathrm{pH}$ 8.0. The concentration of DNA was checked on $0.8 \%$ agarose gel using standard DNA. All isolated DNA checked on gel was diluted to $5 \mathrm{ng} / \mu \mathrm{l}$ for PCR analysis. Equal amounts of genomic DNA from 7,10 and 14 individual plants were mixed and referred as bulk genomic DNA and used for bulked RAPD analyses.

\section{RAPD procedure}

PCR amplification was performed in a final volume of $20 \mu \mathrm{l}$ of reaction mixture containing

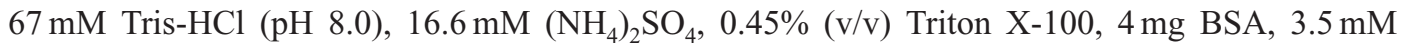
$\mathrm{MgCl}_{2}, 150 \mathrm{mM}$ of each of dATP, dCTP, dGTP and dTTP, $7.5 \mathrm{pmol}$ (15 ng) primer, $25 \mathrm{ng}$ genomic DNA template and 0.5 unit Taq polymerase (Bangalore Genei, India), and finally it was overlaid by 5-10 $\mu 1$ light mineral oil. Amplifications were performed on a DNA thermal cycler PTC-200 (MJ Research, USA) with the cycling program consisting of $94^{\circ} \mathrm{C}$ for $1 \mathrm{~min}, 37^{\circ} \mathrm{C}$ for $1 \mathrm{~min}$ and $72^{\circ} \mathrm{C}$ for $2 \mathrm{~min}$ for 40 cycles followed by $41 \mathrm{st}$ cycle at $37^{\circ} \mathrm{C}$ for $1 \mathrm{~min}$ and finally at $72^{\circ} \mathrm{C}$ for $10 \mathrm{~min}$ extension. The amplified products were kept at $4^{\circ} \mathrm{C}$ until loaded on to the gel. Amplification products were separated by electrophoresis on $1.6 \%$ agarose gel in $0.5 \mathrm{X}$ TBE buffer $(\mathrm{pH} 8.0)$ to which ethidium bromide $(0.5 \mu \mathrm{g} / \mathrm{ml})$ was added for visualization with UV light. Along with the unknown samples 100 base pair DNA ladder was also loaded to know the size of the amplified products. Gels were photographed using Polaroid camera. 


\section{Analysis of data}

RAPD patterns obtained from the individual plants of 5 cultivars were used to calculate the genetic identity index (I) according to the equation (Yu and Pauls 1993):

$$
I=\frac{1}{N} \sum_{i=1}^{N} \frac{2 V_{i}^{(1)} \cdot V_{i}^{(2)}}{\left[V_{i}^{(1)}\right]^{2}+\left[V_{i}^{(2)}\right]^{2}}
$$

$N=$ number of different bands scored for all primers in the 2 cultivars; $V_{i}^{(1)}$ and $V_{i}^{(2)}$ are the frequencies of occurrence of an individual band $i$ in cultivar 1 and 2, respectively. The index of genetic distance $(I G D)$ between 2 cultivars was calculated (Apuya et al. 1988) as:

$$
I G D=-\ln (I)
$$

Based on RAPD patterns of bulked DNA samples the genetic distance $(D)$ between 2 cultivars was calculated following the formula of Swafford and Oslon (1990):

$$
D=-\ln (F)
$$

Where $F$ is an estimate of similarity and was calculated using formula developed by Packer et al. (1991):

$$
F=2 X_{1.2} / X_{1}+X_{2}
$$

where $X_{1.2}$ is the number of amplified DNA fragments with the same molecular weight found in bulked samples of both cultivars, $X_{1}$ is the total number of fragments found in bulked sample of one cultivar and $X_{2}$ is the total number found in the other.

The binary data generated on the basis of presence (1) and absence (0) of the RAPD bands were analyzed for genetic similarity among the bulked samples of 5 cultivars based on Dice's similarity coefficients (s). Dendrogram was constructed by sequential agglomerative hierarchical and nested (SAHN) clustering using the unweighted pair group method with arithmetic mean (UPGMA) algorithm. Missing cases were scored as ' 9 '. A RAPD band was considered polymorphic if the band was present in some accessions and absent in others, monomorphic if the band was present among all the accessions. Ambiguous bands that could not be clearly distinguished were not scored. Computer programme NTSYS-pc (version 2.02) (Rohlf 1993) was used for the present analysis.

\section{Results and discussion}

The 7 random primers namely OPX-01, OPN-05, OPB-20, OPAE-01, OPAL-11, OPT-06 and OPAH-08 used in the present investigation were selected on the basis of good amplifications and depicting high polymorphism among the lucerne cultivars. On average, 5 to 10 bands of the sizes of 200 to 2000 bp were observed on $1.6 \%$ agarose gel (Fig. 1). All reactions were carried out at least twice to maximize the reproducibility of the results and only intense and reproducible PCR bands were taken into consideration. The amplification was performed with individual DNA of five cultivars along with bulk DNA of those cultivars (Fig. 1). In general DNA bands present in more than $50 \%$ of the individual plants were invariably found in bulk DNA of the each cultivar. To the minimum levels, bands observed in 2 individuals (Anand-2 with OPB-20 primer) were observed in bulk DNA sample. However, bands observed in one individual as experienced in cultivars Annad-2 with primer OPT-06; LLC-3 with OPB-20; T-9 and LLC-3 with OPX-01; RL-88, Co-1 and T-9 with OPAL-11 primer have not been observed in bulk DNA samples of respective cultivars. The presence of this band in individual plants was either due to non-specific nature or mis-priming of DNA templates with primers at low annealing temperature usually kept for RAPD with random primers 
Table 1. Index of genetic distance (IGD) and genetic distance (D) calculated from RAPD patterns of 5 cultivars of lucerne using individual and bulked DNA respectively

\begin{tabular}{lllllll}
\hline \hline Cultivars & Index & Anand-2 & RL-88 & T-9 & Co-1 & LLC-3 \\
\hline \multirow{2}{*}{ Anand-2 } & IGD & 0.00 & & & & \\
& D & 0.00 & & & & \\
RL-88 & IGD & 2.69 & 0.00 & & & \\
T-9 & D & 0.07 & 0.00 & & & \\
& IGD & 2.76 & 2.81 & 0.00 & & \\
Co-1 & D & 0.08 & 0.03 & 0.00 & 0.00 & 0.00 \\
LLC-3 & IGD & 2.76 & 2.78 & 2.81 & 2.83 & 0.00 \\
& D & 0.11 & 0.03 & 0.04 & 0.06 & \\
\hline
\end{tabular}

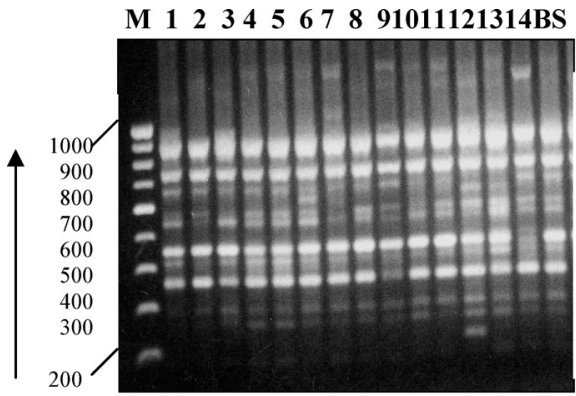

(A)

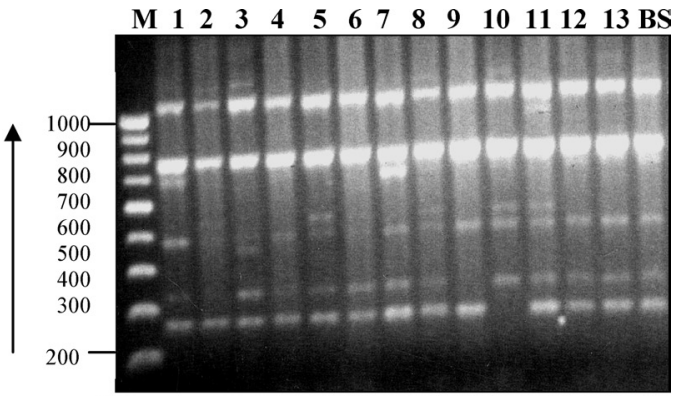

(B)

Fig. 1. (A) RAPD patterns of individual plants of Co-1 and bulk sample (BS) with primer OPT-06 (B) RL88 individual plants and bulk sample with primer OPX-01. M=100 bp DNA ladder as a molecular weight marker

$\begin{array}{llllllllll}M & 1 & 2 & 3 & 4 & 5 & 6 & 7 & 8 & 9\end{array}$

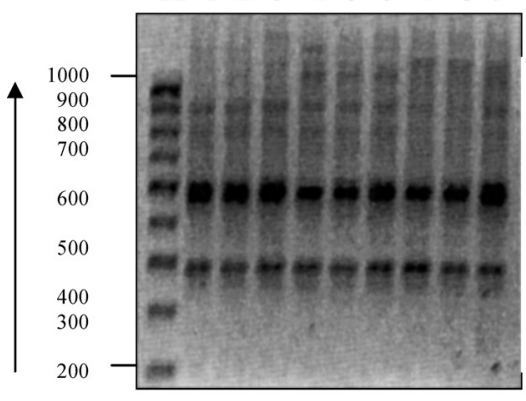

(A)

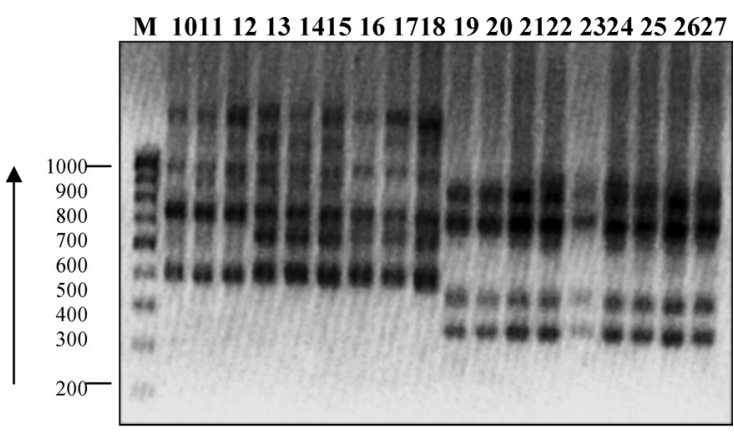

(B)
(C)

Fig. 2. RAPD patterns obtained with bulked genomic DNA samples containing different numbers of T-9 (lanes 1, 2, 3, 10, 11, 12, 19, 20, 21), Co-1 (lanes 4, 5, 6, 13, 14, 15, 22, 23, 24) and LLC-3 (lanes 7, $8,9,16,17,18,25,26,27)$ plants with primers OPAL-11 (A), OPN-05 (B) and OPT-06 (C). RAPD patterns in first lane of each panel are bulked of 7 plants, second lane is bulked of 10 plants and third lane of each panel is bulked of 14 plants. 


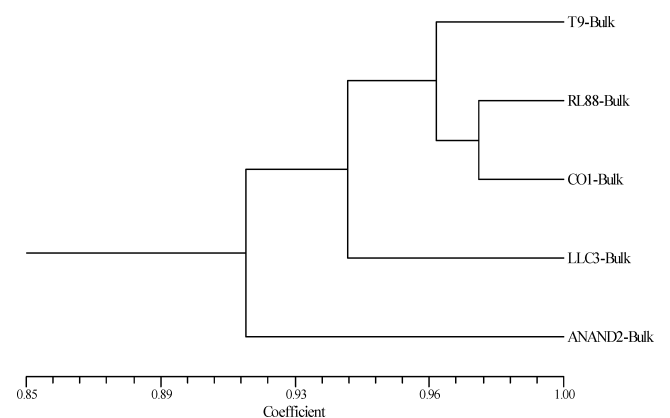

Fig. 3. Dendrogram of RAPD molecular data based on bulked DNA showing genetic similarity between 5 cultivars of lucerne using unweighted pair group method of arithmetic means (UPGMA) analysis. which was otherwise observed absent in bulk DNA samples. The genetic distance (D) values calculated from RAPD patterns obtained with bulked DNA samples of LLC-3, T-9, RL-88, Co- 1 and Anand-2 cultivars ranged from 0.03 to 0.11 and index of genetic distance (IGD) values calculated from RAPD patterns obtained from individual plants of cultivars ranged from 2.69 to 2.83 (Table 1).

Though the ranges of variations in both IGD and D among the cultivars were observed low, maximum IGD was observed between Co1 and LLC-3 whereas the maximum genetic distance (D) was between Co-1 and Anand-2. The order of genetic distance calculated on the basis of bulked DNA samples was not observed similar as index of genetic distance calculated from individual plants of the cultivars. Low variations in genetic distance and index of genetic distance among the cultivars may be attributed to the low variability among the 5 cultivars due to the regular cultivation of these cultivars in close vicinity. Our earlier reports based on Dice similarity coefficients and clustering of cultivars indicated a very high level of similarity among the 5 cultivars (Chandra and Pandey 2005). However, when distinct cultivars were employed the order of D and IGD values for three cultivars of alfalfa namely Dupuits, Anik and Peace were same (Yu and Pauls 1993).

Comparison among RAPD patterns obtained from bulked samples containing DNA from seven, ten and fourteen individuals of T-9, Co-1 and LLC-3 cultivars of lucerne indicated that with most of the primers, the RAPD patterns obtained from the bulk of ten individuals represented the similar patterns observed with larger samples (14) of the same cultivars (Fig. 2) In case of T-9 and LLC-3 cultivars when bulk of 7 individuals was made and amplification was performed with OPN5, a band of the size of $900 \mathrm{bp}$ in T-9 and $1500 \mathrm{bp}$ in LLC-3 was not observed which was otherwise seen in bulk of 10 and 14 individuals DNA (Fig. 2B lanes 10 and 16). This indicated that a minimum of ten individuals could be the best option to study the genetic relatedness study when intracultivars variability is important. The results were demonstrated in studying the genetic relatedness among 5 cultivars utilizing bulked DNA of 10 individual plants. Dendrogram developed with the 61 RAPD bands yielded 2 major clusters (Fig. 3). Cluster 1 was further divided into 2 sub-clusters. Of the 5 cultivars, RL-88 and CO-1 showed maximum homology ( $>96 \%)$. Annad-2 was observed as a most distinct as it formed separate node. Thus, the dendrogram clearly made the distinction among the cultivars when bulk of 10 individual plants were used for genetic assessment.

The present report indicates that RAPD patterns that are characteristics of cultivars can be obtained using bulk of genomic DNA from several individuals of heterogeneous population in PCR reactions with random primers. Results have also indicated bulking of ten individuals (equal amount of DNA) yielded a RAPD pattern that exists for a particular cultivar and thus increases the efficiency of the determining the genetic relatedness among heterogeneous populations or cultivars. With the exception of the faint bands, the bulking of DNA resulted into the superimposition of the patterns seen with the individual plants and thus the patterns are consensus patterns for the common RAPD markers in the cultivars under test. DNA sequences that are common to several plant individuals DNA provided relatively high concentration of template to the bulk and resulted in intense bands in the PCR patterns where those DNA sequences that were found in only a few plants made up too small a proportion of the templates in the mixture that could be efficiently amplified (Yu and Pauls 1993). However, Michelmore et al. (1991) reported that rare RAPD markers could not be de- 
tected in bulk when the DNA samples, they were derived from, represented less than $10 \%$ of the total DNA. Further investigation using such approach may lead to understanding the relatedness among wild species represented by several accessions or heterogeneous natural populations.

\section{Acknowledgements}

Author is thankful to the Director of the Institute and Head of Division for providing the necessary facilities to carry out the present work.

\section{References}

Apuya, N. R., Frazier, B. L., Keim, P., Jill Roth, E. and Lark, K. G. 1988. Restriction fragment length polymorphism as genetic markers in soybean Glycine max (L.) Merrill. Theoretical and Applied Genetics 75: 889-901.

Chandra, A. and Pandey, K. C. 2005. Molecular assessment of heterogeneous alfalfa population using bulk genomic DNA approach. Proc. Intl. Conf. on Plant Genomics and Biotech.: Challenges and Opportunities (IGAU, Raipur), pp. 215-216.

Hazra, C. R. 1995. Advancement in Forage Production Technology. IGFRI, Jhansi, India, pp. 4.

Michelmore, R. W., Paran, I. and Kesseli R. V. 1991. Identification of markers linked to disease-resistance genes by bulked segregant analysis: A rapid method to detect markers in specific genomic regions by using segregating populations. Proceedings of National Academy of Sciences, USA 88: 9828-9832.

Packer, C., Gillbert, D. A., Pusey, A. E. and d O’Brien, S. J. 1991. A molecular genetic analysis of kinship and cooperation in Africa lions. Nature 351: 562-565.

Rohlf, F. J. 1993. NTSYS-Pc Numerical taxonomy and multivariate analysis System, Version 2.02 Applied Biostatics, New York.

Swafford, D. L. and Oslon, C. J. 1990. Phylogeny Reconstruction. In: Molecular Systematic. Hills, D. M. and Moritz, C. (eds.). Sinauer Associates, Sunderland, USA.

Tanksley, S. D. and Orton, T. J. 1983. Isozyme in Plant Genetics \& Breeding, parts A and B, Elsevier, Amsterdam.

— 1983. Molecular markers in plant breeding. Plant Molecular Biology Reporter 1: 3-8.

Williams, J. G. K., Kubehk, A. R., Livak, K. I., Rafalski, J. A. and Tingey, S. V. 1990. DNA polymorphisms amplified by arbitrary primers are useful as genetic markers. Nucleic Acids Research 18: 6531-6535.

Yu, K. and Pauls, K. P. 1993. Rapid estimation of genetic relatedness among heterogeneous populations of alfalfa by random amplification of bulked genomic DNA samples. Theoretical and Applied Genetics 86: 788-794. 